\title{
Lack of association between the TNF- $\alpha$ -308 (G/A) genetic polymorphism and periodontal disease in Brazilians
}

\section{Natascha Giovannetti de \\ Menezes(a) \\ Ana Paula Vieira Colombo(b)}

(a) MSc in Periodontology, School of Dentistry, Federal University of Rio de Janeiro, Brazil.

(b) $\mathrm{PhD}$ in Medical Sciences (Oral Biology), Adjunct Professor, Department of Medical Microbiology, Institute of Microbiology, Federal University of Rio de Janeiro, Brazil.

\section{Corresponding author:}

Natascha Giovannetti de Menezes

Rua Xavier da Silveira, 45, COB 08

Copacabana

Rio de Janeiro - RJ - Brazil

CEP: 22061-010

E-mail: nataschagiovannetti@yahoo.com.br

\begin{abstract}
This study evaluated the frequency of the tumor necrosis factor-alpha (TNF- $\alpha$ ) -308 G/A polymorphism in Brazilians with periodontal health $(\mathrm{PH}=51)$, chronic periodontitis $(\mathrm{CP}=74)$ and generalized aggressive periodontitis $(\mathrm{GAgP}=38)$. Human DNA was obtained from mouthwash samples and TNF- $\alpha$ genotyping was performed by PCR and RFLP analyses. Differences in clinical and genetic parameters among groups were sought by Kruskal-Wallis, $\chi^{2}$ and Fisher's exact tests. The allele $-308 \mathrm{G}$ was detected in $91.7 \%$, whereas the allele $-308 \mathrm{~A}$ was found in $35.4 \%$ of all subjects. No significant differences were observed in the frequency of these alleles $\left(\chi^{2}=2.610, \mathrm{p}>0.05\right)$ and the genotypes $\mathrm{G} / \mathrm{G}, \mathrm{G} /$ $\mathrm{A}$, and $\mathrm{A} / \mathrm{A}\left(\chi^{2}=2.547, \mathrm{p}=0.636\right)$ among groups. The data suggest that the TNF- $\alpha-308$ G/A polymorphism is not associated with periodontitis in this Brazilian population.
\end{abstract}

Descriptors: TNF-alpha; Periodontal diseases; Genetic polymorphism; PCR. 


\section{Introduction}

The cytokine TNF- $\alpha$ has been found at high levels in gingival crevicular fluid and gingival tissues from periodontitis lesions. ${ }^{1}$ TNF- $\alpha$ was clearly identified as a potent inducer of tissue destruction and bone resorption in different forms of periodontal disease. ${ }^{2}$ A guanine $(\mathrm{G})$ to adenine $(\mathrm{A})$ transition at position -308 of the TNF- $\alpha$ promoter affects a consensus sequence for a binding site of the transcription factor AP-2. ${ }^{3}$ Carriage of the rare -308 A allele is associated with significantly greater TNF- $\alpha$ production and transcription. ${ }^{3}$ In addition, the A allele has been associated with increased risk for various non-related infectious and inflammatory diseases, ${ }^{4}$ including periodontitis. ${ }^{5,6}$ In contrast, other investigators have failed to corroborate the association between this polymorphism and increased risk for periodontal diseases. ${ }^{7-11}$ The frequency of genetic polymorphisms may vary considerably among distinct ethnic groups, so that the application of such markers for diagnosis and prognosis of periodontitis should be examined in different populations. ${ }^{12}$ This study determined the frequency of the -308 (G/A) TNF- $\alpha$ alleles and genotypes in individuals with different periodontal status from a Brazilian population.

\section{Material and Methods Human subjects and clinical assessments}

A total of 163 adult subjects who sought dental treatment at the Dental School of the Federal University of Rio de Janeiro were recruited for the study. Informed consent was obtained from all individuals. The study protocol was approved by the Review Committee for Human Subjects of the Clementino Fraga Filho University Hospital. Exclusion criteria included pregnancy, use of local or systemic antimicrobials in the previous 6 months, diabetes, and other systemic conditions that could affect the periodontal status. All subjects had at least 10 teeth and were over 18 years of age. Clinical measurements were performed at 6 sites/tooth and included probing depth (PD), clinical attachment level (CAL), presence or absence of supragingival biofilm (SB), bleeding on probing (BOP) and suppuration (SUP). Subjects were categorized into: periodontal health controls $(\mathrm{PH}=51$; no sites with $\mathrm{PD}$ and/or $\mathrm{CAL}>3 \mathrm{~mm}$ and no more than $10 \%$ of sites with $\mathrm{BOP})$; chronic periodontitis ( $\mathrm{CP}=74$; at least $10 \%$ of teeth with PD and/or CAL $\geq 5 \mathrm{~mm}$, or $20 \%$ of teeth with $\mathrm{PD}$ and/or $\mathrm{CAL} \geq 4 \mathrm{~mm}$ ); and generalized aggressive periodontitis $(\mathrm{GAgP}=38 ; \geq 30 \%$ of teeth with PD and/or CAL $\geq 5 \mathrm{~mm}$, or $\geq 60 \%$ of teeth with $\mathrm{PD}$ and/or $\mathrm{CAL} \geq 4 \mathrm{~mm})$. Patients were defined (by self-reporting) as White, African-Brazilian, or others. Individuals were classified as smokers, never-smokers and former smokers (subjects who had stopped smoking for at least 2 years).

\section{Determination of -308 (G/A) TNF- $\alpha$ genotypes}

Mouthwash samples were obtained from patients as previously described..$^{13}$ Human genomic DNA was isolated from samples by using the QIAmp DNA Mini Kit (QIAGEN, Valencia, CA, USA), and stored at $-20^{\circ} \mathrm{C}$. PCR was performed in a $50 \mu \mathrm{L}$ reaction mix containing $100 \mathrm{ng}$ of DNA, $5 \mu \mathrm{L}$ of $10 \mathrm{X}$ PCR buffer $(100 \mathrm{mM}$ TrisHCl, $\mathrm{pH} 8.3,500 \mathrm{mM} \mathrm{KCl})$, $1.5 \mathrm{mM} \mathrm{MgCl}_{2}, 0.2 \mathrm{mM}$ of each dNTP, $1.25 \mathrm{U}$ of

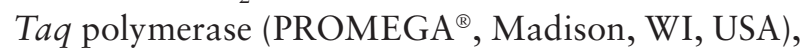
and $0.2 \mathrm{pM}$ of each primer $^{14}$ (sense primer 5' -AGG CAA TAG GTT TTG AGG GCC AT- 3' and antisense primer 5' -TCC TCC CTG CTC CGA TTC CG- 3'; Bio-Synthesis ${ }^{\circledR}$, Inc., Lewisville, TX, USA). The PCR program included a step of $95^{\circ} \mathrm{C}$ for 10 min, followed by 38 cycles of $94^{\circ} \mathrm{C}$ for $1 \mathrm{~min}, 57^{\circ} \mathrm{C}$ for $1 \mathrm{~min}$ and $72^{\circ} \mathrm{C}$ for $1 \mathrm{~min}$. Subsequently, $20 \mu \mathrm{L}$ of the amplicon (107 bp fragment) were digested with $5 \mathrm{U}$ of $\mathrm{Nco} I\left(\mathrm{PROMEGA}^{\circledR}\right)$ at $37^{\circ} \mathrm{C}$ overnight and the generated DNA fragments were analysed by electrophoresis on a $2.5 \%$ agarose gel.

\section{Statistical analysis}

Analyses were performed using the software SPSS (SPSS Inc ${ }^{\circledR}$ v.13 Chicago, IL, USA). Clinical measurements were computed for each subject and averaged across subjects within the groups. Differences on clinical parameters among groups were sought using Kruskal-Wallis, Mann-Whitney (between pairs of groups) and $\chi^{2}$ tests. The frequency of alleles and genotypes were compared among groups by $\chi^{2}$ and Fisher's exact tests, and odds ratios with $95 \%$ confi- 
dence intervals were determined. In order to control for age and race, the data were stratified by these categories and analyzed by Kruskal-Wallis and $\chi^{2}$ tests. A 5\% significance level was set for all analyses.

\section{Results}

\section{Demographic and clinical features}

The demographic data of the 3 clinical groups are summarized in Table 1. PH and GAgP patients were significantly younger than CP individuals $(\mathrm{p}<0.01)$. A greater $\%$ of White patients was observed in the PH group (81\%), whereas the CP and GAgP groups presented a higher proportion of African-Brazilians $(22 \%$ and $14 \%$, respectively) and individuals of mixed racial background $(19 \%$ and $50 \%$, respectively) ( $\mathrm{p}=0.002)$. In general, most of the patients were never-smokers $(78.5 \%)$. Nevertheless, a higher frequency of current and former smokers with chronic periodontitis was detected $(\mathrm{p}<0.001)$.

Table 2 shows that statistically significant differences among groups were observed for all clinical parameters $(\mathrm{p}<0.01)$. When pairs of groups were compared, no significant differences were found for number of missing teeth, BOP, SB, SUP, and $\mathrm{CAL}>6 \mathrm{~mm}$ between the $\mathrm{CP}$ and GAgP groups. In order to control for smoking and race, comparisons of clinical parameters among groups were carried out only in never-smokers and White individuals. Even though, differences among groups were sta-

Table 1 - Demographic parameters (mean \pm SD) of Periodontally Healthy $(\mathrm{PH})$, Chronic Periodontitis $(\mathrm{CP})$, and Generalyzed Aggressive Periodontitis (GAgP) subjects of the study population.

\begin{tabular}{|c|c|c|c|c|}
\hline \multicolumn{2}{|c|}{ Parameters } & $\begin{array}{c}\mathrm{PH} \\
(\mathrm{N}=51)\end{array}$ & $\begin{array}{c}C P \\
(N=74)\end{array}$ & $\begin{array}{c}\text { GAgP } \\
(N=38)\end{array}$ \\
\hline \multicolumn{2}{|r|}{ Age ${ }^{*} \neq$} & $30 \pm 10$ & $48 \pm 12$ & $31 \pm 6$ \\
\hline \multicolumn{2}{|c|}{ (\%) Males } & 31 & 41 & 18 \\
\hline \multirow{3}{*}{$\begin{array}{l}\text { Race } \\
(\%)^{* *}\end{array}$} & Whites & 81 & 59 & 36 \\
\hline & African-Brazilians & 8 & 22 & 14 \\
\hline & Others & 11 & 19 & 50 \\
\hline \multirow{3}{*}{$\begin{array}{l}\text { Smoking } \\
(\%)^{* *}\end{array}$} & Never-smokers & 88 & 61 & 100 \\
\hline & Former-smokers & 8 & 27 & 0 \\
\hline & Current-smokers & 4 & 12 & 0 \\
\hline
\end{tabular}

"Refers to $p<0.01$, Kruskal-Wallis test, and $\ddagger$, to Mann-Whitney test; " refers to $p<0.01, \chi^{2}$ test. tistically significant for all clinical measurements ( $\mathrm{p}<0.001$; data not shown).

\section{Frequency of the TNF- $\alpha$ (-308 G/A) alleles and genotypes}

The allele distributions of the TNF- $\alpha$ among clinical groups are shown in Table 3. No differences were found between observed and expected distributions of genotypes for the $\mathrm{PH}$ control group. Thus, the allele distribution was assumed to be in HardyWeinberg equilibrium. A high incidence of allele $G$ was observed in all groups. Likewise, the \% of subjects carrying at least one copy of the $G$ allele was greater than subjects carrying allele A. However, no significant differences in the distribution of these alleles were found among groups $\left(\chi^{2}=2.610, p>0.05\right.$ for allele frequency; $\chi^{2}=1.01, p=0.604$ for $\mathrm{G}+$ and $\chi^{2}=2.12, \mathrm{p}=0.345$ for $\mathrm{A}+$ individuals). When $\mathrm{PH}$ subjects were compared with the CP or GAgP patients, no significant differences between groups were observed for allele frequency. Also, no significant differences in the distribution of these alleles

Table 2 - Full-mouth clinical parameters (mean \pm SD) of Periodontally Healthy (PH), Chronic Periodontitis (CP), and Generalyzed Aggressive Periodontitis (GAgP) subjects of the study population.

\begin{tabular}{|c|c|c|c|c|}
\hline & Parameters & $\begin{array}{c}\mathrm{PH} \\
(\mathrm{N}=51)\end{array}$ & $\begin{array}{c}C P \\
(N=74)\end{array}$ & $\begin{array}{c}\text { GAgP } \\
(N=38)\end{array}$ \\
\hline \multicolumn{2}{|c|}{$\mathrm{N}$ of missing teeth " +} & $2.3 \pm 3.6$ & $5.5 \pm 4.8$ & $4.4 \pm 4.7$ \\
\hline \multicolumn{2}{|r|}{$\mathrm{PD}(\mathrm{mm})^{* \dagger \ddagger}$} & $1.7 \pm 0.3$ & $2.7 \pm 0.9$ & $3.3 \pm 0.9$ \\
\hline \multicolumn{2}{|r|}{$\mathrm{CAL}(\mathrm{mm})^{*}+$} & $1.8 \pm 0.3$ & $3.6 \pm 1.5$ & $3.8 \pm 1.1$ \\
\hline \multirow{9}{*}{ 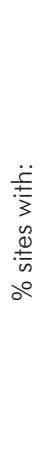 } & $B O P *+$ & $4.3 \pm 4.3$ & $41.2 \pm 26.6$ & $48.6 \pm 28.4$ \\
\hline & SB ${ }^{*}+$ & $13.4 \pm 16$ & $46.3 \pm 30$ & $37.4 \pm 29$ \\
\hline & SUP * † & 0 & $0.6 \pm 1.6$ & $2.3 \pm 4.9$ \\
\hline & $\mathrm{PD} \leq 4 \mathrm{~mm}$ *† & 100 & $88 \pm 16$ & $75 \pm 20.3$ \\
\hline & PD 5-6 mm* & 0 & $8.5 \pm 9.4$ & $19 \pm 14$ \\
\hline & $\mathrm{PD}>6 \mathrm{~mm}^{*} \dagger \ddagger$ & 0 & $3.5 \pm 8.5$ & $6 \pm 8.5$ \\
\hline & $\mathrm{CAL} \leq 4 \mathrm{~mm}^{*} \dagger \ddagger$ & 100 & $73 \pm 27$ & \pm 24 \\
\hline & CAL 5-6 mm*† & 0 & $16 \pm 15$ & $24 \pm 14$ \\
\hline & $\mathrm{CAL}>6 \mathrm{~mm}^{*}+$ & 0 & $11 \pm 17$ & $10 \pm 14$ \\
\hline
\end{tabular}

Refers to $p<0.01$ (Kruskal-Wallis test); ${ }^{\dagger}$ refers to $p<0.01$ (MannWhitney between $\mathrm{PH}$ and $\mathrm{CP}$, and $\mathrm{PH}$ and $\mathrm{GAgP})$; $₹$ refers to $p<0.01$ (Mann-Whitney between $\mathrm{CP}$ and $\mathrm{GAgP}) ; \mathrm{PD}=$ pocket depth; $\mathrm{CAL}=$ clinical attachment level; $\mathrm{BOP}=$ bleeding on probing; $\mathrm{SB}=$ supragingival biofilm; SUP = suppuration. 
Table 3 - Frequency of alleles in the TNF- $\alpha-308$ G/A gene polymorphism in Periodontally Healthy (PH), Chronic Periodontitis $(C P)$, and Generalyzed Aggressive Periodontitis (GAgP) subjects of the study population.

\begin{tabular}{|c|c|c|c|c|c|c|}
\hline & & $\mathrm{PH}$ & $\mathrm{CP}$ & GAgP & PH vs. $\mathrm{CP}^{\cdots *}$ & PH vs. GAgP ${ }^{\cdots *}$ \\
\hline & & $\mathrm{n}=51$ & $\mathrm{n}=74$ & $\mathrm{n}=38$ & OR $(95 \% \mathrm{Cl})$ & OR $(95 \% \mathrm{Cl})$ \\
\hline \multirow{2}{*}{ Allele frequency ${ }^{*}+$} & TNF- $\alpha-308 G$ & $72.5 \%$ & $81 \%$ & $81.6 \%$ & \multirow{2}{*}{$0.616(0.34-1.12)$} & \multirow{2}{*}{$0.596(0.29-1.23)$} \\
\hline & TNF- $\alpha-308 A$ & $27.5 \%$ & $19 \%$ & $18.4 \%$ & & \\
\hline \multirow{2}{*}{ Polymorphic allele positivity "* } & $G+\S$ & $88.4 \%$ & $92.3 \%$ & $94.4 \%$ & $1.5(0.43-5.82)$ & $4.5(0.40-12.3)$ \\
\hline & $A+\perp$ & $44.2 \%$ & $31 \%$ & $33.3 \%$ & $0.59(0.25-1.25)$ & $0.69(0.25-1.58)$ \\
\hline
\end{tabular}

"Values represent the $\%$ in which the alleles appear of the total possible times $(2 n)$ that they may occur in each group $(P H=102 ; C P=148 ; G A g P=76)$; ${ }^{\dagger} \chi^{2}=2.610, p>0.05$; " Percentage of individuals who carry at least one copy of each polymorphic allele; ${ }^{\S} \chi^{2}=1.01, p=0.604 ;{ }^{\perp} \chi^{2}=2.12, p=0.345$ "Not significant (Fisher's exact test).

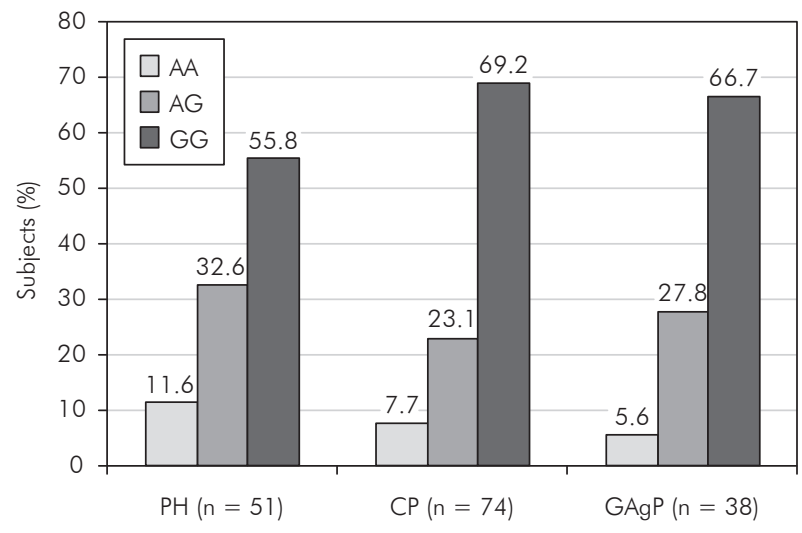

Graph 1 - Bar chart of the distribution of the TNF- $\alpha$ 308 G/A genotypes in Periodontally Healthy (PH), Chronic Periodontitis (CP), and Generalyzed Aggressive Periodontitis (GAgP) subjects of the study population. No significant differences were observed among groups $\left(\chi^{2}=2.547\right.$, $p=0.636)$.

were found when only never-smoker and White subjects were included in the analyses (data not shown).

As seen in Graph 1, no significant differences among groups were observed regarding the distributions of the three genotypes AA, AG and GG $\left(\chi^{2}\right.$ $=2.547, \mathrm{p}=0.636$ ).

\section{Discussion}

Periodontal diseases are considered to be complex diseases. Complex diseases are typically polygenic. ${ }^{12}$ Disease modifying genes associated with susceptibility and severity of periodontitis have been proposed, but very little is known about which genes may be involved in these diseases. ${ }^{12}$ The current study investigated the frequency of the TNF- $\alpha-308$ G/A alleles and genotypes in Brazilians with different periodon- tal conditions. Our results showed that the carriage rate of the rare allele A was slightly higher in the $\mathrm{PH}$ controls compared to diseased groups, but no significant differences among groups were found. The frequency of allele A varied widely in most of the studies carried out in different populations (range $3 \%-32 \%)^{7-9,11,15-17}$ Despite these differences, our findings are in agreement with the majority of the literature data that failed to show an association of this polymorphism with susceptibility and/or severity of periodontal disease. . $^{-9,11,15-17}$

Regarding the G/G, G/A and A/A genotypes, a similar distribution was observed among the groups as well. Usually, the $-308 \mathrm{~A}$ allele is considered to be the marker of disease susceptibility due to the upregulatory effect of this allele on the cytokine production. However, Folwaczny et al. ${ }^{9}$ (2004) and Sakellari et al. ${ }^{11}$ (2006) reported low frequencies for the A/A genotype in periodontitis patients $(2 \%-4 \%)$, whereas this genotype was not detected in periodontally healthy subjects. Other studies did not find the A/A genotype neither in patients nor in controls.,17 Our data indicated that the A/A genotype tended to be more prevalent in the $\mathrm{PH}$ group $(11.6 \%)$ in relation to the $\mathrm{CP}(7.7 \%)$ and $\mathrm{GAgP}(5.6 \%)$ groups, although these differences were not significant. Very few studies have reported some correlation between TNF- $\alpha$ polymorphism and periodontitis. Some authors found a significant high frequency of the $G / G$ genotype in severe periodontitis patients, ${ }^{6,16}$ whereas Lin et al..$^{5}$ (2003) reported a significant association between the A allele and moderate-to-advanced periodontitis. Other TNF- $\alpha$ polymorphisms have been 
investigated..$^{15,17}$ Only Soga et al. ${ }^{17}$ (2003) showed a significant association between TNF- $\alpha-1031,-863$ and -857 polymorphisms and severe periodontitis in Japanese individuals.

The inconsistent results observed in the literature could be attributed to several factors related to the definition of disease, population heterogeneity, environmental and demographic confounding risk factors. ${ }^{12}$ Although differences in age, ethnicity, gender and smoking history were observed among the subject groups in the current study, the distribution of alleles and genotypes has not changed when the data were independently analyzed in subgroups of patients (data not shown). The sample size in this study was small, thus careful interpretation of the data is necessary. Lack of association between genotypes and clinical status may be due to small sample size, particularly for alleles of low prevalence. Nevertheless, we observed a quite elevated carriage rate for the rare allele A compared to other investigations. ${ }^{7,9,11,17}$

Defining a subject population in relation to the type of periodontal disease may also contribute to significant differences among genetic studies. It is likely that overlapping of clinical phenotypes exists between different forms of periodontitis, regardless of the diagnostic criteria used. Even though we used commonly accepted criteria to differentiate clinical groups, comparing our findings with those of other studies is quite difficult due to the different classification systems used.

\section{References}

1. Engebretson SP, Lamster IB, Herrera-Abreu M, Celenti RS, Timms JM, Chaudhary AG et al. The influence of interleukin gene polymorphism on expression of interleukin 1 beta and tumor necrosis factor-alpha in periodontal tissue and gingival crevicular fluid. J Periodontol. 1999;70(6):567-73.

2. Graves DT, Delima AJ, Assuma R, Amar S, Oates T, Cochran D. Interleukin-1 and tumor necrosis factor antagonists inhibit the progression of inflammatory cell infiltration toward alveolar bone in experimental periodontitis. J Periodontol. 1998;69(12):1419-25.

3. Abraham LJ, Kroeger KM. Impact of the -308 TNF promoter polymorphism on the transcriptional regulation of the TNF gene: relevance to disease. J Leukoc Biol. 1999;66(4):562-6.
Finally, the genetic basis for periodontitis may not be related to a single genetic variant, but may be influenced by multiple genes acting synergistically with environmental factors to increase or decrease the likelihood of developing a disease. The TNF cluster region exhibits a high degree of linkage disequilibrium with other polymorphic nearby genes involved in inflammatory responses..$^{18}$ For instance, Fassmann et al. ${ }^{8}$ (2003) suggested that combined genotypes of the TNF- $\alpha-308$ G/A and LT- $\alpha$ +252 G/A polymorphisms may influence the susceptibility to chronic periodontitis. Thus, the analysis of a single genetic polymorphism might be meaningless for determining a genetic risk factor for periodontal diseases. Instead, combinations of different genotypes for possible gene-gene interactions should be evaluated in these studies.

\section{Conclusion}

Based on our results, the TNF- $\alpha-308$ G/A polymorphism is not associated with increased susceptibility to or severity of periodontitis in this particular Brazilian population.

\section{Acknowledgments}

This work was supported in part by the National Council for Scientific and Technological Development (CNPq), 470103/2004-3; and by the Research Foundation for Financial Support in the State of Rio de Janeiro, E-26/ 170.562/2004.

4. Wilson AG, di Giovine FS, Duff GW. Genetics of tumour necrosis factor-alpha in autoimmune, infectious, and neoplastic diseases. J Inflamm. 1995;45(1):1-12.

5. Lin L, Pan YP, Yin LY. Study on the correlation of cytokine gene polymorphism with chronic periodontitis. Shanghai Kou Qiang Yi Xue. 2003;12(6):456-9.

6. Qian W, Zhang J, Zhang Y. [The relationship between tumor necrosis factor A-308 gene polymorphism and susceptibility of severe periodontitis in adults] [Article in Chinese]. Zhonghua Kou Qiang Yi Xue Za Zhi. 2002;37(2):126-8.

7. Donati M, Berglundh T, Hytonen AM, Hahn-Zoric M, Hanson LA, Padyukov L. Association of the -159 CD14 gene polymorphism and lack of association of the -308 TNFA and Q551R 
IL-4RA polymorphisms with severe chronic periodontitis in Swedish Caucasians. J Clin Periodontol. 2005;32(5):474-9.

8. Fassmann A, Holla LI, Buckova D, Vasku A, Znojil V, Vanek J. Polymorphisms in the +252 (A/G) lymphotoxin-alpha and the $-308(\mathrm{~A} / \mathrm{G})$ tumor necrosis factor-alpha genes and susceptibility to chronic periodontitis in a Czech population. J Periodontal Res. 2003;38(4):394-9.

9. Folwaczny M, Glas J, Torok HP, Mende M, Folwaczny C. Lack of association between the TNF alpha G -308 A promoter polymorphism and periodontal disease. J Clin Periodontol. 2004;31(11):449-53.

10. Kornman KS, Crane A, Wang HY, di Giovine FS, Newman MG, Pirk FW et al. The interleukin-1 genotype as a severity factor in adult periodontal disease. J Clin Periodontol. 1997;24(1):72-7.

11. Sakellari D, Katsares V, Georgiadou M, Kouvatsi A, Arsenakis M, Konstantinidis A. No correlation of five gene polymorphisms with periodontal conditions in a Greek population. J Clin Periodontol. 2006;33(11):765-70.

12. Kinane DF, Shiba H, Hart TC. The genetic basis of periodontitis. Periodontol 2000. 2005;39:91-117.

13. Laine ML, Farre MA, Crusius JB, van Winkelhoff AJ, Pena AS. The mouthwash: a non-invasive sampling method to study cytokine gene polymorphisms. J Periodontol. 2000; 71(8):1315-8.

14. Wilson AG, di Giovine FS, Blakemore AI, Duff GW. Single base polymorphism in the human tumour necrosis factor alpha (TNF alpha) gene detectable by NcoI restriction of PCR product. Hum Mol Genet. 1992;1(5):353.

15. Galbraith GM, Steed RB, Sanders JJ, Pandey JP. Tumor necrosis factor alpha production by oral leukocytes: influence of tumor necrosis factor genotype. J Periodontol. 1998;69(4): 28-33.

16. Galbraith GM, Hendley TM, Sanders JJ, Palesch Y, Pandey JP. Polymorphic cytokine genotypes as markers of disease severity in adult periodontitis. J Clin Periodontol. 1999;26(11): 705-9.

17. Soga Y, Nishimura F, Ohyama H, Maeda H, Takashiba S, Murayama Y. Tumor necrosis factor-alpha gene (TNF-alpha) -1031/-863, -857 single-nucleotide polymorphisms (SNPs) are associated with severe adult periodontitis in Japanese. J Clin Periodontol. 2003;30(6):524-31.

18. Wilson AG, de Vries N, Pociot F, di Giovine FS, van der Putte LB, Duff GW. An allelic polymorphism within the human tumor necrosis factor alpha promoter region is strongly associated with HLA A1, B8, and DR3 alleles. J Exp Med. 1993;177(2):557-60. 